\title{
Collagen Fiber Orientation Is Coupled with Specific Nano-Compositional Patterns in Dark and Bright Osteons Modulating Their Biomechanical Properties
}

Kilian E. Stockhausen, Mahan Qwamizadeh, Eva M. Wölfel, Haniyeh Hemmatian, Imke A. K. Fiedler, Silja Flenner, Elena Longo, Michael Amling, Imke Greving, Robert O. Ritchie, Felix N. Schmidt, ${ }^{\#}$ and Björn Busse*,\#

Cite This: ACS Nano 2021, 15, 455-467

Read Online

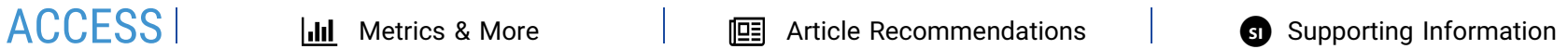

ABSTRACT: Bone continuously adapts to its mechanical environment by structural reorganization to maintain mechanical strength. As the adaptive capabilities of bone are portrayed in its nano- and microstructure, the existence of dark and bright osteons with contrasting preferential collagen fiber orientation (longitudinal and oblique-angled, respectively) points at a required tissue heterogeneity that contributes to the excellent fracture resistance mechanisms in bone. Dark and bright osteons provide an exceptional opportunity to deepen our understanding of how nanoscale tissue properties influence and guide fracture mechanisms at larger length scales. To this end, a comprehensive structural, compositional, and mechanical

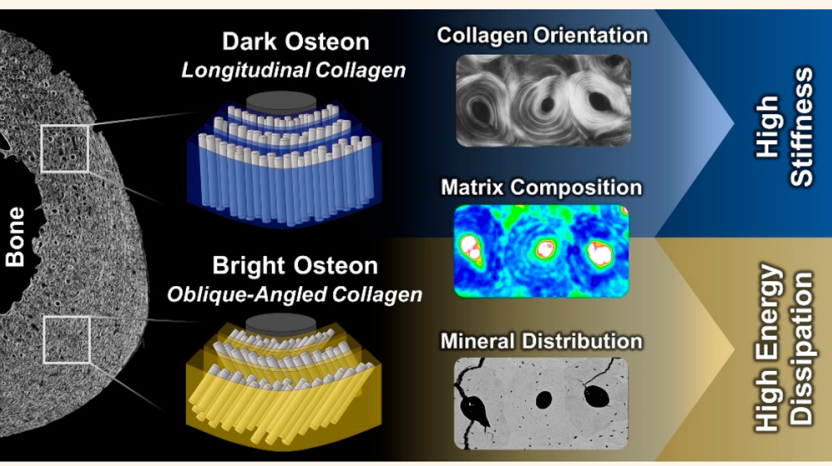
assessment is performed using circularly polarized light microscopy, synchrotron nanocomputed tomography, focused ion beam/scanning electron microscopy, quantitative backscattered electron imaging, Fourier transform infrared spectroscopy, and nanoindentation testing. To predict how the mechanical behavior of osteons is affected by shifts in collagen fiber orientation, finite element models are generated. Fundamental disparities between both osteon types are observed: dark osteons are characterized by a higher degree of mineralization along with a higher ratio of inorganic to organic matrix components that lead to higher stiffness and the ability to resist plastic deformation under compression. On the contrary, bright osteons contain a higher fraction of collagen and provide enhanced ductility and energy dissipation due to lower stiffness and hardness.

KEYWORDS: bone, osteon, collagen fiber orientation, mineral aggregates, biomechanics

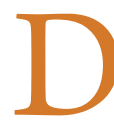

uring bone remodeling, cortical bone is continuously reorganized in response to mechanical stimuli to ensure adequate bone quality on all hierarchical levels. ${ }^{1,2}$ In this process, osteoclasts remove bone tissue and void volumes are subsequently filled in by osteoblasts with new bone matrix to form osteons. ${ }^{3}$ Osteons are the basic structural unit of cortical bone and consist of concentric lamellar structures surrounding a central Haversian canal. While osteons are predominantly oriented parallel to the long axis of the bone, the orientation of collagen fibers within individual lamellae can differ considerably leading to a number of proposed models over the years. ${ }^{4-8}$ While no universal model for the collagen arrangement in bone exists, an impact of preferentially aligned collagen fibers and bone mineral particles on the biomechanical function is postulated. The collagen fibers are reinforced by bone mineral particles to form a spatially related composite material where the mineral long axis is coaligned with the collagen fibers that provides bone its unique mechanical properties. ${ }^{9,10}$ More recently, the understanding of mineral and collagen assembly has advanced with

Received: June 8, 2020

Accepted: December 11, 2020

Published: January 6, 2021 

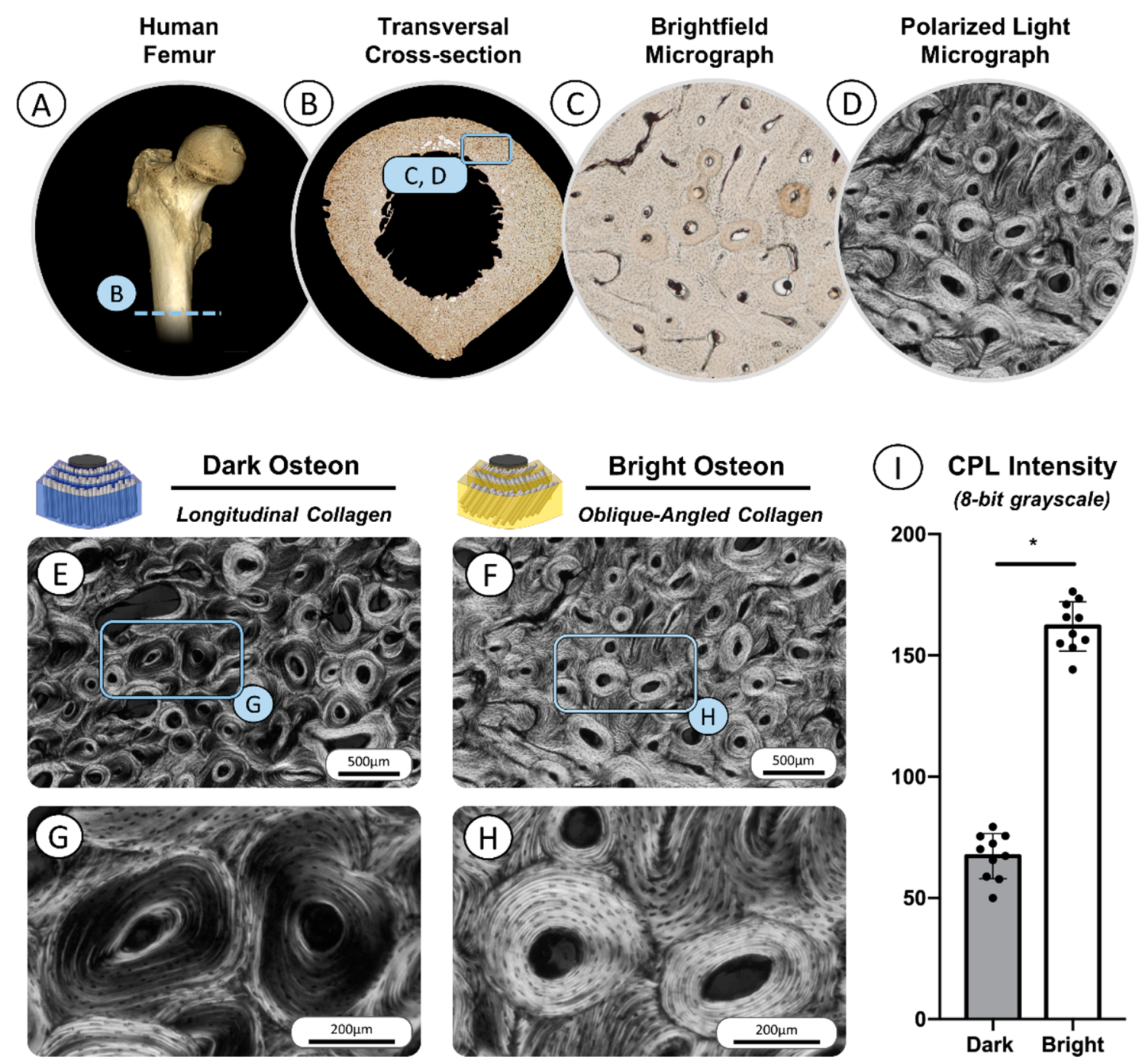

Figure 1. (A, B) Femoral bone was obtained during autopsy, and cross sections were cut from the mid-diaphysis. (C) At the microstructural level, femoral cortical bone is composed of secondary remodeled osteons surrounded by interstitial bone. (D) Preferential collagen fiber orientation (CFO) remains hidden under brightfield microscopy but can be visualized using circularly polarized light microscopy (CPL): osteons composed of oblique orientated collagen fibers appear bright, while osteons composed of collagen fibers parallel with the osteon axis appear dark. ${ }^{48}(\mathrm{E}-\mathrm{H})$ CPL was used to identify 20 osteons of contrasting preferential CFO for subsequent assessment. (I) Brightness of the masked CPL images reflects the predominant collagen fiber orientation.

studies showing that bone mineral is fractal-like and hierarchically assembled at the nanoscale ${ }^{11}$ and that localized differences between the orientation of mineral nanocrystals and collagen fibrils exist within single lamellae that might add an additional layer of mechanical adaptation toward compressive loading. ${ }^{12}$

During skeletal growth and throughout life, the mechanical behavior of bone is closely correlated to its structure and composition, even though the mechanical properties in juvenile bone are explained by different intrinsic properties compared to adult bone. ${ }^{13,14}$ In health, bone is able to withstand complex physiological loading patterns by capable fracture resistance mechanisms, both intrinsic and extrinsic. $^{15-17}$ Many factors guide the fracture resistance of bone including the structural integrity on the nano- and microscale, the bone mineral density distribution, the mineral quality, and the accumulation of microcracks. ${ }^{18-21}$ This extends to the organic part of the matrix where alterations in collagen quality have been shown to have an adverse effect on the mechanical competence. $^{22-24}$ The importance of collagen for fracture resistance is emphasized by clinically challenging disorders like osteogenesis imperfecta or Paget's disease, both of which are characterized by impaired collagen formation and organization leading to increased fracture susceptibility. ${ }^{25-27}$ Additionally, the orientation of collagen fibers is considered as an contributor to bone's ability to resist fracture. ${ }^{28,29}$ When viewed under polarized light, the predominant collagen fiber orientation (CFO) can be quantified; osteons composed of oblique orientated collagen fibers appear bright, while osteons composed of collagen fibers parallel to the osteon axis appear dark. $^{30,31}$ Structurally, bright osteons are characterized by predominant CFOs of $\pm 45^{\circ}$ with respect to the osteon axis, whereas dark osteons are distinguished by longitudinal collagen fibers. $^{31}$

So far, most studies seized on the idea that dark osteons are better able to resist tensile forces and bending while bright osteons, assembled of oblique-angled collagen fibrils, can better withstand compressive forces and torsion. ${ }^{32,33}$ It was proposed that the collagen fiber organization is an excellent predictor of cortical bone strength and that the distribution 


\section{Synchrotron Nano-Computed Tomography}

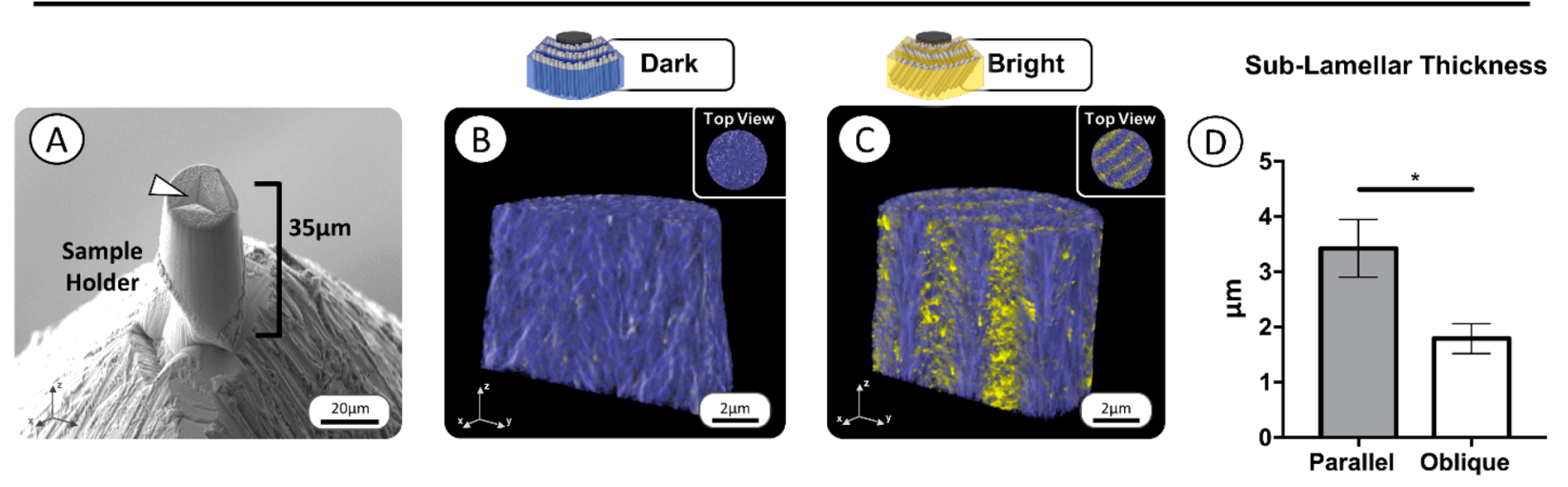

FIB-SEM Imaging

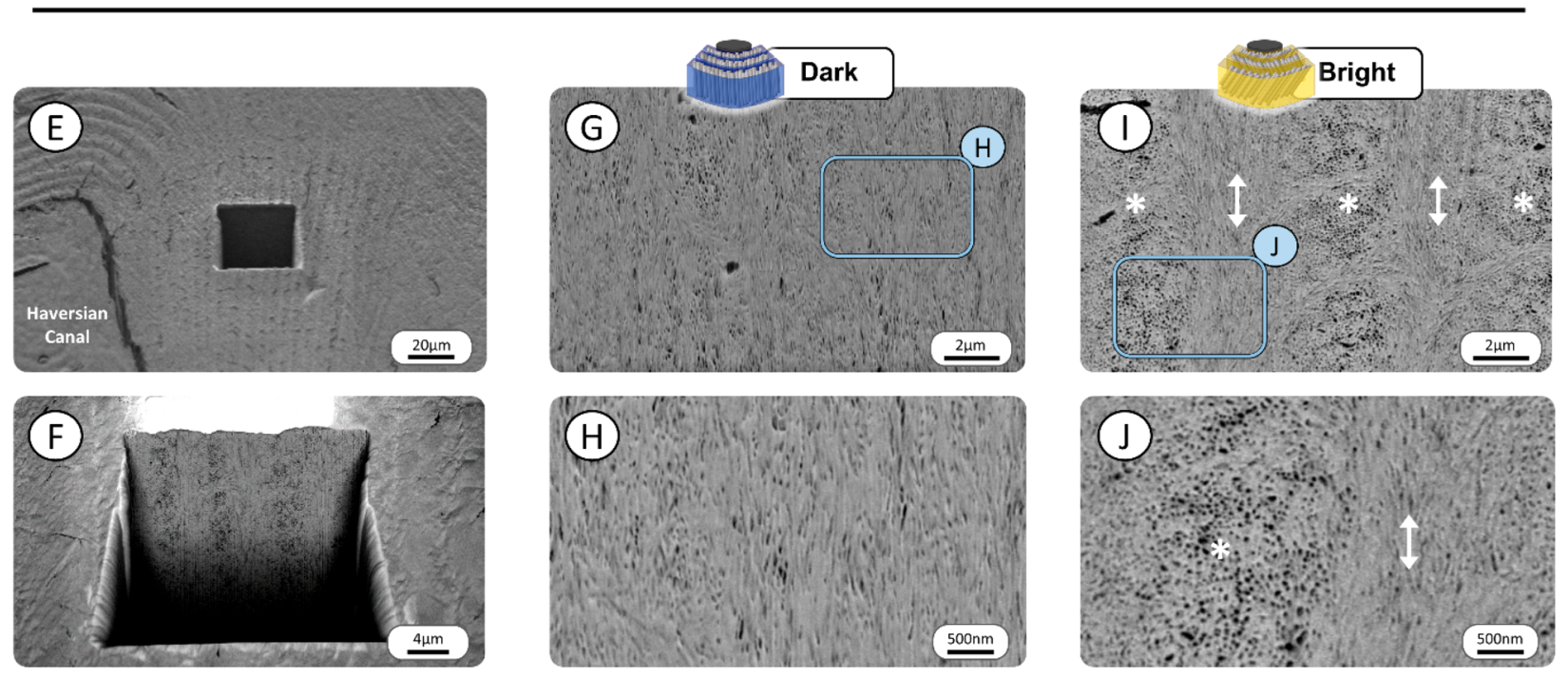

Figure 2. (A) Using FIB-SEM, cylindrical bone volumes below the nanoindentations (white arrow) were extracted. (B) Using synchrotron nanocomputed tomography with Zernike phase contrast the nanoscale collagen orientation is visualized. Structurally rather homogeneous, collagen fibers run predominantly parallel to the long axis in dark osteons. (C) In bright osteons, a lamellar pattern of volumes being composed of parallel fibers (blue) and oblique-angled fibers (yellow) with respect to the osteon axis becomes evident. (D) Parallel-fibered lamellae were found to be significantly thicker compared to lamellae composed of oblique-angled fibers. (E, F) FIB-SEM imaging was used to visualize the internal structure within dark and bright osteons. $(\mathrm{E}, \mathrm{H})$ Transversely oriented trenches were milled into the osteon to expose an imaging plane with radial-longitudinal orientation with respect to the Haversian canal. (G, $H)$ Consistent with the tomography findings, dark osteons are characterized by collagen fibers running predominantly parallel to the long axis. (I, J) Bright osteons display the characteristic lamellar pattern with fibrils being oriented parallel (double-headed arrows) and oblique-angled to the analyzed plane (asterisk). The sublamellar thicknesses conform with the values reported in (D).

pattern of both osteon types, neglecting the degree of mineralization, corresponds to that of the loading forces acting on the bone. ${ }^{34-36}$ In quadrupedal mammalians, where angulation of the joints leads to significant bending stresses, $^{37,38}$ the distribution of dark and bright osteons coincides with the distribution of tensile and compressive stresses. $^{39-41}$ The dependency of population densities of distinct osteon types with specific loading modes suggests that collagen fibers align according to specific strain modes and serve different mechanical functions. ${ }^{42-44}$ However, in bipedal human femoral bone, the diaphysis is primarily loaded in compression with little impact of bending and tensile forces. $^{45-47}$ In view of this rather uniform loading scenario, spatial changes in the preferential CFO of osteons might serve further mechanical functions beyond the resistance to tensile and compressive stresses indicating a more profound mechanical function of dark and bright osteons. This is further supported by the fact that, even though the overall CFO pattern appeared nonrandomly distributed, no single pattern of $\mathrm{CFO}$ was found to exist in the human diaphyseal femur, suggesting that the microstructure is sensitive to individual adaptation. ${ }^{30}$ In this study, we aim to reinterpret the role of dark and bright osteons in bone that is predominantly under compression to elucidate the necessity of both types to coexist within the femoral diaphysis.

While the structural properties of dark and bright osteons have been studied in the past, the composition and its impact on mechanical properties are still unknown. As bone derives its strength and toughness from its hierarchical assembly, dark and bright osteons provide an exceptional opportunity to deepen our understanding of how nanoscale tissue properties influence and guide fracture mechanisms at larger length scales. To this end, we applied synchrotron nanocomputed tomography, quantitative backscattered electron imaging 
( $\mathrm{qBEI})$, focused ion beam milling combined with scanning electron microscopy (FIB-SEM), Fourier transform infrared spectroscopy (FTIR), and nanoindentation testing to assess the structure, composition and biomechanical properties of 20 dark and bright osteons. In order to predict how the preferential CFO affects the biomechanical behavior of bone on the overlying hierarchical levels, finite element models are generated. We hypothesize that osteons with contrasting types of preferential CFO (oblique-angled versus longitudinal) present with distinct differences in compositional and local biomechanical properties. Despite the compression-dominant loads present in the femur, this would indicate that individual osteons are highly sensitive to their mechanical surrounding and serve different mechanical functions providing bone locally with more stiffness or ductility where needed.

\section{RESULTS AND DISCUSSION}

As the adaptive capabilities of bone to the mechanical environment are portrayed in its microstructure and composition, the existence of dark and bright osteons with contrasting predominant CFO types points at a required heterogeneity of the tissue matrix beneficial for the unique properties of bone. To unravel the necessity of both types of osteons to exist within the femoral diaphysis we comprehensively assess the structure, composition, and mechanical properties of dark osteons composed of collagen fibers running parallel to the long axis and bright osteons predominantly built from oblique-angled fibers. In the human femoral middiaphysis, circularly polarized light microscopy (CPL) was employed to identify and quantify the preferential CFO of individual osteons that remains hidden under brightfield microscopy (Figure 1A-D). Increasing brightness corresponds to a shift in predominant $\mathrm{CFO}$ toward more oblique-angled collagen fibers (Figure 1E-H). Quantitative analysis in individual osteons excluding the Haversian canal area consistently shows significantly higher brightness in bright compared to dark osteons $(67.22 \pm 9.31$ versus $162.00 \pm$ 10.17, $p<0.001$ ) (Figure 1I). The marked differences in brightness values obtained by CPL highlight fundamental structural variations in terms of the predominant $\mathrm{CFO}$ between different osteons within the same individual. Comparing undecalcified and decalcified ground sections in terms of CPL brightness, it was found that both samples displayed similar brightness values independent of the mineralization state (Figure S1). This clearly shows that the changes in CPL brightness are attributable to orientation shifts of optically anisotropic collagen and are not affected by the mineralization profile of individual osteons.

The changes in CFO, as detected by CPL, are verified using synchrotron nanocomputed tomography with Zernike phase contrast and FIB-SEM imaging (Figure 2). Utilizing phase contrast, phase variations of the beam propagating through the bone specimen can be visualized allowing for the assessment of the spatial organization of collagen fibers. ${ }^{49,50}$ In the threedimensional visualization obtained, it was found that in dark osteons collagen fibers indeed run parallel with the long axis of the bone (Figure 2B). No transition between neighboring lamellae is visible supporting the reported view that dark osteons are structurally rather homogeneous. ${ }^{31}$ On the other hand, bright osteons display a considerable degree of heterogeneity within its CFO. Here, a distinct lamellar pattern with changing $\mathrm{CFO}$ is present similar to the proposed plywood structural models of osteons. (Figure 2C and Supporting
Information videos 1 and 2). An arching of collagen fibers is observed with fiber angles ranging from +90 to $-90^{\circ}$ with respect to the long axis of the osteons where the longitudinally oriented fraction of collagen fibers corresponds to the darkened lamellae of the otherwise bright osteon under CPL. The thickness of the lamellae composed of longitudinally oriented collagen fibers was found to be significantly higher compared to lamellae built from oblique-angled fibers $(3.42 \pm$ $0.55 \mu \mathrm{m}$ versus $1.79 \pm 0.27 \mu \mathrm{m}, p<0.001$ ) (Figure $2 \mathrm{D}$ ) which is consistent with previous studies. ${ }^{51}$ The structural organization is further validated by FIB-SEM imaging where transversely oriented trenches were milled into the osteon to expose the internal matrix organization (Figure 2E,F). Here, a higher degree of CFO homogeneity was observed in dark osteons with collagen fibers running predominantly parallel to the long axis. In agreement with the nanocomputed tomography findings and consistent with previously published data, ${ }^{52}$ bright osteons are composed of lamellae with obliqueangled collagen fibers that are bordered by lamellae built from parallel-oriented fibers (Figure 2G-J). Interestingly, the lamellar layout of bright osteons is also represented in quantitative backscattered electron images (qBEI) of transversely sectioned osteons, where individual lamellae with a thickness of $\sim 6 \mu \mathrm{m}$ are clearly visible whereas the lamellar pattern is hardly evident in the dark osteons (Figure 3A,B).

\section{Osteocyte Lacunae Characteristics}
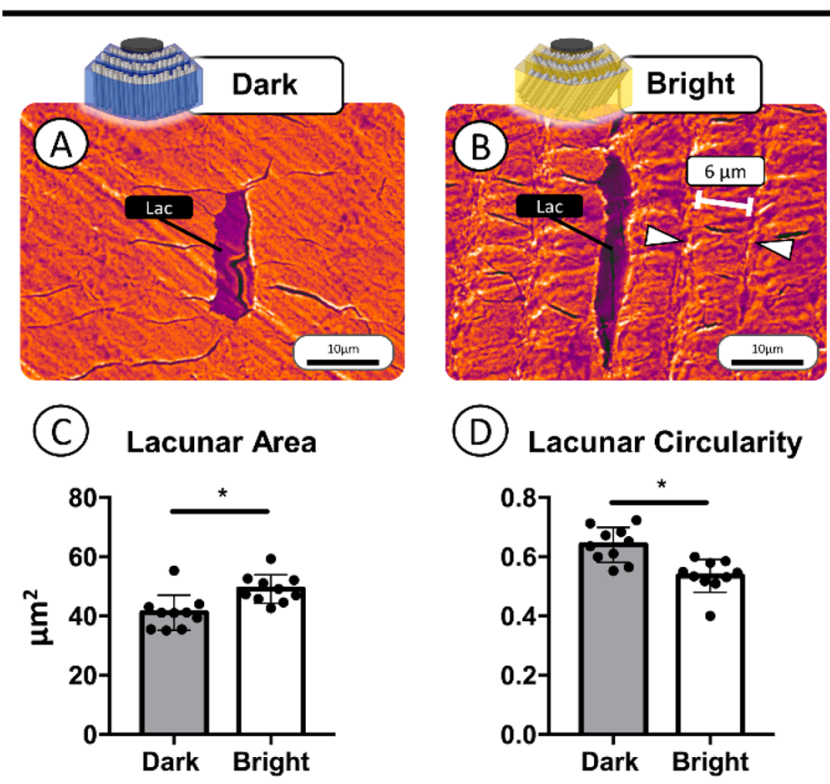

Figure 3. (A, B) Structurally, no lamellar pattern is visible in dark osteons whereas bright osteons display a lamellar pattern with $\sim 6$ $\mu \mathrm{m}$ total thickness (white arrows) around osteocyte lacunae (lac). (C, D) The osteocyte lacunar area is smaller in size in dark osteons and is characterized by a higher circularity index indicating a rounder shape.

Here it is important to mention that the lamellar thickness as assessed in qBEI images refers to the total thickness of a repeating unit of lamellae. ${ }^{53}$ As visualized by nanocomputed tomography and FIB-SEM imaging, a lamellar unit contains one sublamellae of predominantly parallel-oriented and one sublamellae of oblique-angled collagen fibers. Significant variations in osteocyte lacunar area and shape between both osteon types were also measured from the acquired qBEI 
images. Osteocyte lacunar areas are smaller in size in dark osteons compared to bright osteons $\left(41.17 \pm 5.92 \mu \mathrm{m}^{2}\right.$ versus $\left.49.21 \pm 4.83 \mu \mathrm{m}^{2}, p<0.001\right)$ and are characterized by a higher circularity index $(0.631 \pm 0.059$ versus $0.536 \pm 0.056, p<$ 0.001 ) representative of a rounder shape (Figure 3C,D). As osteoblasts are aligned with the collagen fibers they lay down during the formation phase, ${ }^{54}$ this supports the view that the long axis of the osteocyte lacunae is aligned with the preferential CFO. ${ }^{55}$ No difference in osteocyte lacunar density was measured between dark and bright osteons (0.00083 \pm 0.00024 versus $\left.0.00091 \pm 0.00033 \# / \mu \mathrm{m}^{2}, p=0.588\right)$. Despite the differences in osteocyte lacunar area and collagen fiber orientation, the canaliculi were found to be oriented perpendicular to the osteonal lamellae and extending radially from the central Haversian canal in both osteon types (Figure S2 and Supporting Information videos 1 and 2).

The content of mineral between the two structurally opposing types of osteons was quantified using qBEI where lower brightness values signify a lower and higher brightness values a higher mineral content (Figure 4A,B). Both qBEI histograms of dark and bright osteons present an inverse lognormal frequency distribution, but the dark osteons are characterized by a higher peak and a smaller tail at the lowcalcium end (Figure 4C). Quantitative analysis of the qBEI histograms revealed significant differences in the mineral distribution. A higher mean calcium content $\left(\mathrm{Ca}_{\text {mean }}\right)$ was quantified in osteons with a predominant longitudinal collagen fiber orientation. The $\mathrm{Ca}_{\text {mean }}$ is $5.68 \%$ higher in dark osteons compared to the bright ones $(26.25 \pm 0.32$ versus $24.84 \pm 0.34$ Ca wt \%, $p<0.001$ ) (Figure 4D). The peak calcium content $\left(\mathrm{Ca}_{\text {peak }}\right)$ displays the same pattern with a $5.42 \%$ higher peak mineralization in dark osteons (26.67 \pm 0.36 versus $25.30 \pm$ $0.32 \mathrm{Ca}$ wt $\%, p<0.001$ ) (Figure $4 \mathrm{E}$ ). In support of the higher mean and peak calcium content, dark osteons have a higher percentage of bone area exhibiting a high mineral content $\left(\mathrm{Ca}_{\text {high }}, p<0.001\right)$ and a lower percentage of bone area with a low mineral content $\left(\mathrm{Ca}_{\text {low }}, p<0.001\right.$ ) (Figure $4 \mathrm{~F}, \mathrm{G}$ ) compared to bright osteons. Overall, the qBEI data shows a higher bone mineral content in osteons with preferentially longitudinal oriented collagen fibers indicating a connection between the CFO and degree of mineralization. Since osteons undergo quick primary mineralization during remodeling followed by secondary mineralization that proceeds over longer periods of time, cortical bone presents with a heterogeneous mineralization profile. ${ }^{56,57}$ Consequently, a higher mean calcium content usually points toward a higher tissue age and maturation. ${ }^{58-60}$ From our findings regarding the mineralization, this would infer that dark osteons are on average older and more mature compared to bright osteons. However, this seems unlikely as this would require a continuous change in collagen fiber orientation from obliqueangled to longitudinal over time.

To assess how the higher degree of mineralization is associated with changes in the organic phase, FTIR was performed to assess the ratio of mineral-to-matrix (MMR). Here, the differences measured by qBEI are supported by the FTIR results: dark osteons are characterized by a higher MMR compared to bright osteons $(3.21 \pm 0.17$ versus $2.80 \pm 0.18, p$ $<0.001$ ) which corresponds to an increase of $14.77 \%$ (Figure 5A-D). Moreover, the MMR positively correlates with the mean calcium content showing that dark osteons indeed contain more mineral $(r=0.7292, p<0.001)$ (Figure 5E). Consistent with previous studies, ${ }^{61,62}$ a ring of elevated MMR

\section{Quantitative Backscattered Electron Imaging}
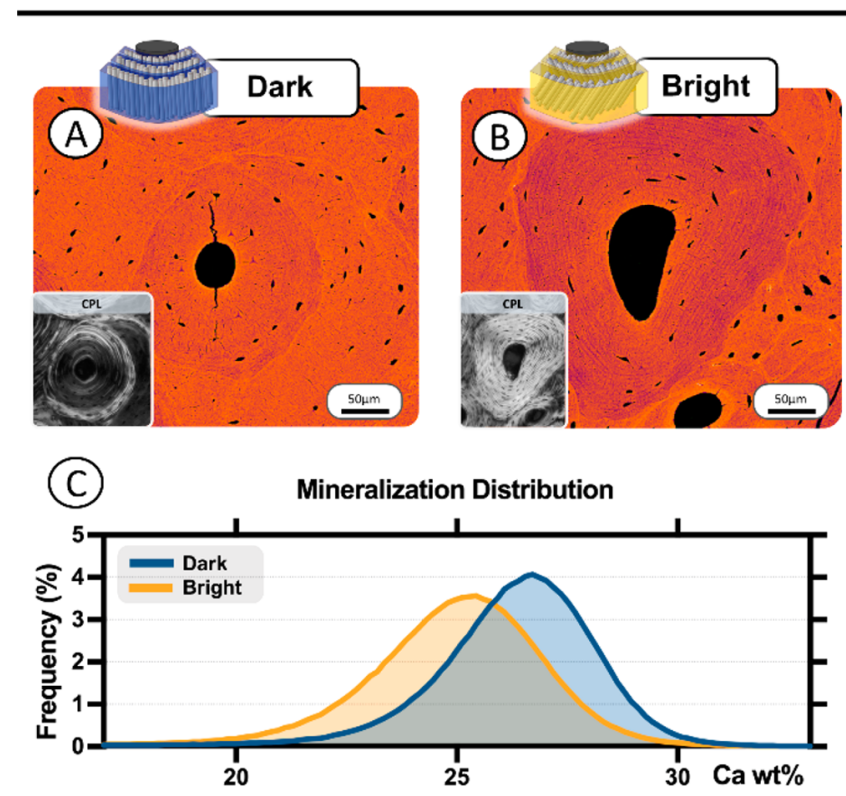

(D)

Calcium Mean
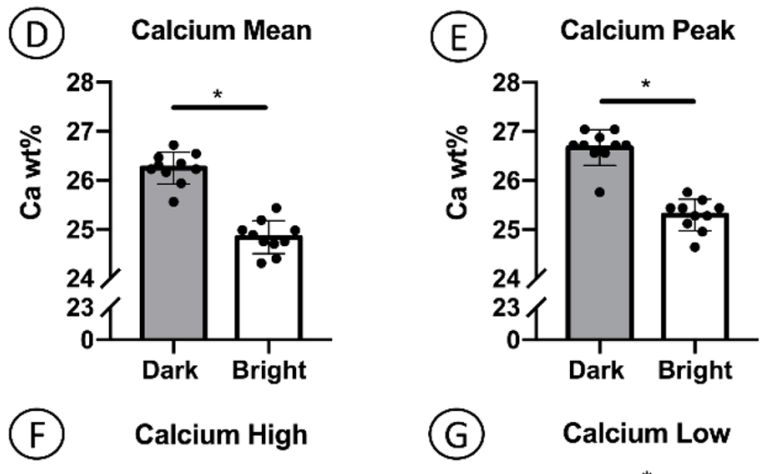

Calcium High
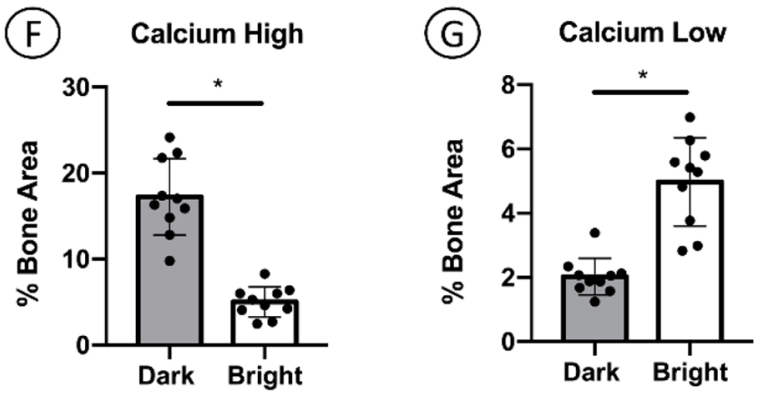

Figure 4. (A, B) Using qBEI, the mineral density is quantified. (C) Histogram analysis reveals a higher mineralization in dark osteons. (D, E) Both mean and peak calcium contents are increased. (F, G) Accordingly, a smaller percentage of bone area is regarded as lowly mineralized, and a higher percentage as highly mineralized.

was measured toward the center of the Haversian canal, both in dark and bright osteons. It was found that the thickness of the ring with elevated MMR correlates positively with the osteon wall thickness $(r=0.681, p<0.001)$. Calculating the ratio of the high-MMR ring thickness and the osteon wall thickness revealed no statistical differences between dark and bright osteons $(0.223 \pm 0.037$ versus $0.2144 \pm 0.030 \mu \mathrm{m}, p=$ 0.603 ) (Figure S3). The higher MMR was accompanied by a higher carbonate-to-phosphate ratio (CPR) in dark osteons $(0.01463 \pm 0.00044$ versus $0.01370 \pm 0.00028,6.79 \%$ higher, $p$ $<0.001)$ which also correlated positively with the mean calcium content $(r=0.4914, p<0.001)$ (Figure 5F,G). The higher amount of carbonate substitution for phosphate in the mineral crystals is often linked to more mature and crystalline 


\section{Fourier Transform Infrared Spectroscopy}
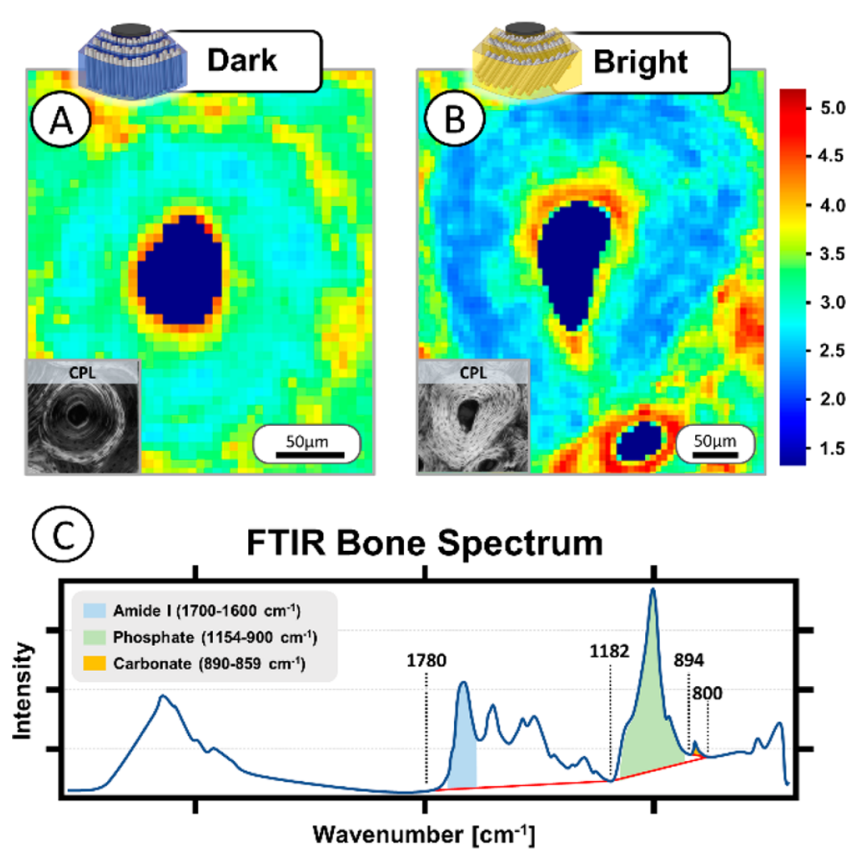

Mineral-To-Matrix Ratio

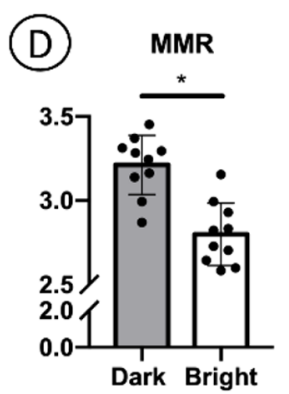

(E) MMR vs Calcium Mean

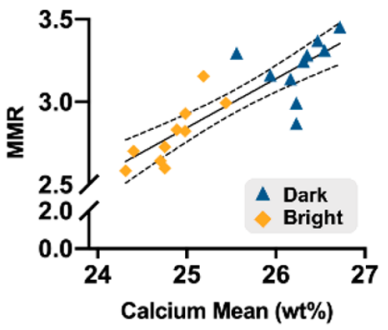

Carbonate-To-Phosphate Ratio

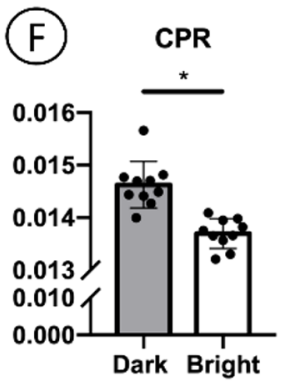

(G) CPR vs Calcium Mean

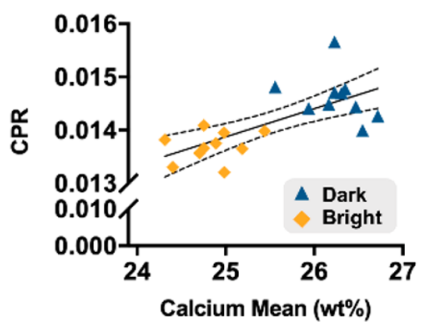

Figure 5. (A, B) Representative maps of the mineral-to-matrix ratio (MMR) of dark and bright osteons where each pixel represents individual spectra. (C, D) Differences measured by qBEI are supported by the FTIR results: dark osteons are characterized by a higher MMR compared to bright osteons, which correlates positively with the mean calcium content. (E, F) Amount of carbonate substitution for phosphate (CPR) in the mineral crystals is increased and correlates positively with the mean calcium content. mineral crystals. In general, MMR and CPR increase with advancing age, ${ }^{63,64}$ and regardless of developmental age, the highest CPRs are present in the oldest bone. ${ }^{65,66}$ However, CPR may also be an indicator of mineralization speed and secondary hypermineralization ${ }^{67}$ which points toward a favored accelerated mineralization in dark osteons for biomechanical purposes.

Taken together, our findings suggest that the bone matrix is sensitive to structural and compositional adaptions on the osteonal level which define its localized biomechanical competence. As the inorganic mineral phase of the bone matrix has a higher stiffness compared to the organic collagen phase, the degree and quality of mineralization is also an indicator for the mechanical competence of bone. ${ }^{68-71} \mathrm{We}$ speculate that the revealed differences in mineral content between dark and bright osteons are related to their specific ultrastructure and play a functional role in providing biomechanical competence rather than being a result of tissue aging.

To link the structural and compositional disparities of dark and bright osteons to the local biomechanical properties, nanoindentation testing was performed (Figure 6A,B). In agreement with the observed trends in the mineralization pattern assessed by qBEI and FTIR, both the hardness and stiffness measured via nanoindentation are significantly higher in dark osteons indicating a greater resistance to deformation. The elastic modulus was $31.05 \%$ higher in the dark osteons $(25.28 \pm 1.12 \mathrm{GPa}$ versus $19.29 \pm 1.54 \mathrm{GPa}, p<0.001)$ (Figure 6C). Correspondingly, the hardness was $33.33 \%$ higher in dark osteons compared to bright osteons $(0.96 \pm 0.08 \mathrm{GPa}$ versus $0.72 \pm 0.09 \mathrm{GPa}, p<0.001$ ) (Figure $6 \mathrm{D}$ ). The mean calcium content correlated positively with the elastic modulus and hardness $(\mathrm{r}(\mathrm{E})=0.885, \mathrm{r}(\mathrm{H})=0.788, p<0.001)$ (Figure $6 \mathrm{E}, \mathrm{F})$ and the preferential CFO negatively $(\mathrm{r}(\mathrm{E})=0.888, \mathrm{r}(\mathrm{H})$ $=0.766, p<0.001$ ) (Figure 6G,H).

As an interim summary, it can be noted that both types of osteons are clearly distinguished in terms of their structure, composition, and biomechanical properties. Dark osteons with longitudinal CFO are characterized by a higher degree of mineralization along with a higher ratio of inorganic to organic matrix components that lead to higher stiffness (higher elastic modulus) and the ability to resist plastic deformation (higher hardness). On the contrary, bright osteons with oblique-angled CFO contain a higher fraction of collagen and could provide enhanced ductility and energy dissipation due to lower stiffness and hardness.

Since nanoindentation testing displays biomechanical properties on the lamellar level of osteons, the mechanical behavior of dark and bright osteons itself is not fully represented. To predict how changes in CFO on the nanoscale affect the tissue-level biomechanical properties, finite element models were generated. The fundamental building blocks of the matrix, namely the mineralized collagen fibrils, were modeled as representative volume elements (RVEs) taking into account their orthotropic mechanical properties. The overlying hierarchical levels (mineralized collagen fibers, osteonal lamellae, and full osteons) were then modeled for different orientations of the collagen fibrils leading to two key findings. First, the implications of the observed structural and compositional disparities between dark and bright osteons on the mechanical properties as assessed by nanoindentation have been validated by the outcomes of the FEM models. Shifting the fiber orientation from $45^{\circ}$ to $0^{\circ}$ resulted in the effective 


\section{Nanoindentation Testing}
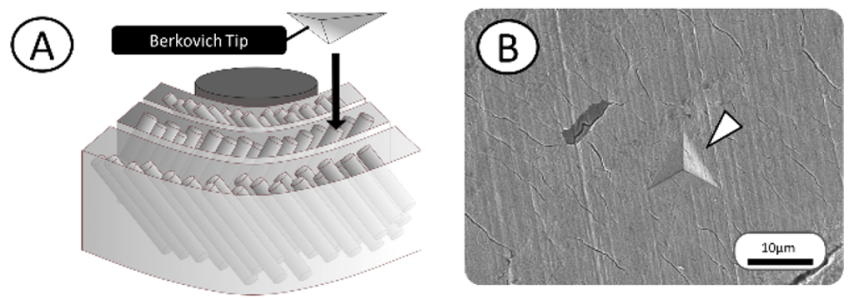

(C)

Elastic Modulus
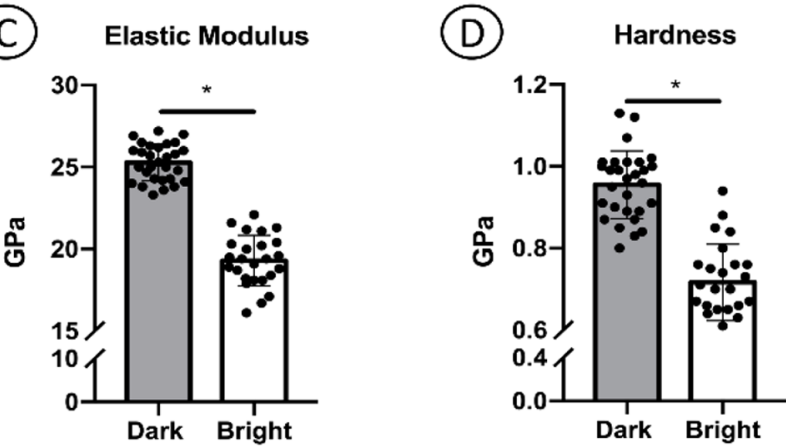

Indentation Correlations
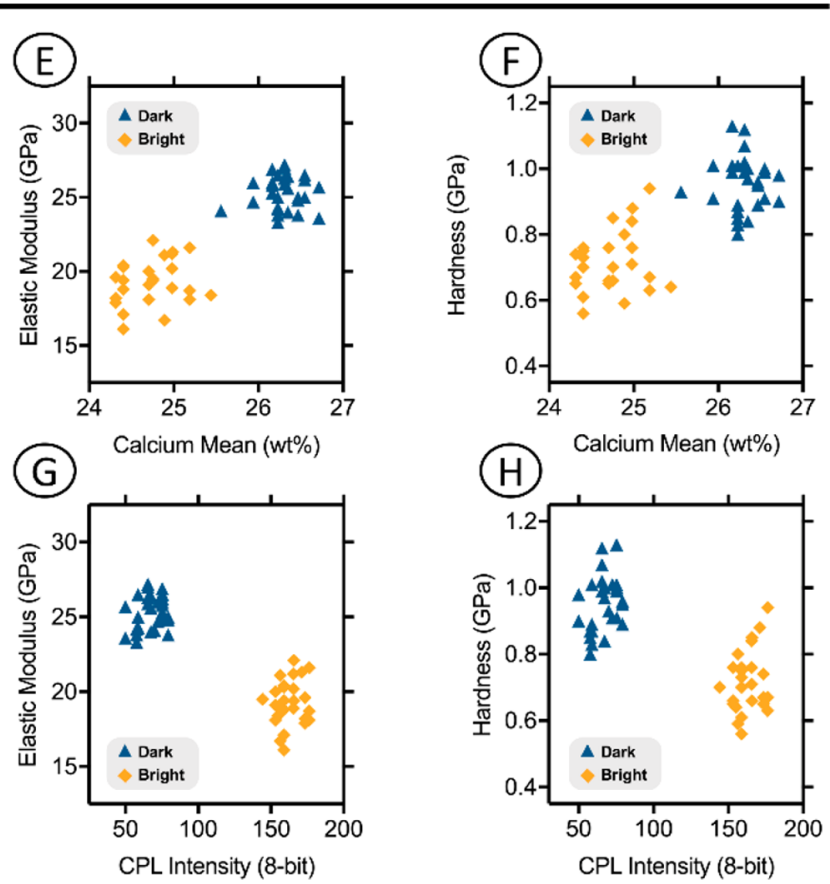

Figure 6. (A) Local biomechanical properties were assessed by nanoindentation testing and (B) successful indents were verified using electron microscopy (white arrow). (C, D) The elastic modulus and hardness are significantly higher in dark osteons. (E, F) Both parameters correlated positively with the mean calcium content and (G, H) negatively with the predominant collagen orientation.

modulus in the direction of indentation $\left(E_{1}\right)$ being increased $26.70 \%$ for the lamellar level (Table 1). The FEM model predicts an elastic modulus of $26.15 \mathrm{GPa}$ for dark and 20.64 GPa for bright osteons, which is in good agreement with the experimentally measured values of $25.28 \pm 1.12$ and $19.29 \pm$ $1.54 \mathrm{GPa}$, respectively (considering the nanoindentation results being representative of the lamellar level). The detailed engineering elastic constants of the coated fiber and lamellae RVE are summarized in Table 1.

Second, the obtained elastic constants were used to predict the effective elastic modulus $E_{\text {eff }}$ of whole osteons (Table 2). On the osteonal level, the influence of the higher mineralized and, hence, stiffer interstitial bone on the mechanical properties becomes evident: the higher the assumed elastic modulus of the interstitial bone the higher the effective modulus of the osteon RVE. Still, a clear difference between different types of collagen orientation is observed: for dark osteons $\left(0^{\circ}\right), E_{\text {eff }}$ is $14.38 \%$ higher compared to bright osteons $\left(45^{\circ}\right)$ (averaged over equal assumed elastic modulus of interstitial bone). When comparing dark osteons to osteons with alternating CFO between neighboring lamellae, $E_{\text {eff }}$ is $7.20 \%$ higher in dark osteons. However, alternating lamellae results in $6.70 \%$ higher $E_{\text {eff }}$ when compared to bright osteons. This clearly shows the adaptive capabilities and biomechanical implications of dark and bright osteons to either serve as a stiff building block of bone or to conduce as an energy dissipating module, both to prevent fractures on larger length scales.

Although we are aware of the established view that CFO pattern should reflect the loading history of the femur, with dark osteons occupying volumes that are subjected to tensile stress and bright osteons being present in areas under compression, based on the compositional results obtained in this study we propose an alternative view on the existence of dark and bright osteons and their mechanical functions. We postulate that dark osteons are predominantly found in regions where a higher degree of stiffness is required since more deformation is created in low stiffness materials when they are subjected to uniaxial stress, either compression or tension. From a mechanistic point of view, it is beneficial for the human femur to have less lateral movement along the anterior and posterior axis, thus a higher fraction of osteons with longitudinally oriented collagen fibers with a higher mineral content that provides additional stiffness. ${ }^{72}$ On the other hand, regions that experience some bending stresses (while still being predominantly loaded in compression) would benefit from oblique-angled collagen fibers with a lower mineral content and an improved ability to dissipate energy. In general, nanoand microscale heterogeneity of the bone matrix composition and mechanical properties is considered beneficial for the mechanical competence at larger length scales. ${ }^{73-75}$ In healthy bone, continuous remodeling processes maintain a constant tissue heterogeneity for better damage resistance. Healthy bone can hamper the initiation and propagation of microcracks while enabling remodeling processes to repair the affected bone volume. The mineralization profile of individual osteons, $^{61}$ the higher mineralization and accumulation of cross-links in interstitial bone ${ }^{76}$ and the stiffness mismatch at cement lines ${ }^{77}$ all contribute to tissue heterogeneity that guides the toughening mechanisms of bone. Based on our findings, we believe that structural heterogeneity at the osteonal level extends to the organic phase of the matrix: bone tissue can react to changed loading modes to modulate its nanostructural arrangement in functional interaction with its compositional properties to build more dark osteons in case of increased need of stiffness (compressive/tensile loading) or bright osteons to dissipate energy.

It can also be speculated that the osteon heterogeneity might be another mechanism that preserves the mechanical competence of bone. Rather than being considered "old" tissue, the nanostructural heterogeneity could serve as a 
Table 1. FEM Calculated Elastic Moduli for the Coated Collagen Fiber and Osteonal Lamellar Level Assuming 0 and $45^{\circ}$ of Collagen Fiber Orientation ${ }^{a}$

\begin{tabular}{|c|c|c|c|c|c|c|c|c|c|c|c|c|}
\hline RVE, orientation & $\mathrm{E}_{1}$ & $\mathrm{E}_{2}$ & $\mathrm{E}_{3}$ & $\mathrm{G}_{12}$ & $\mathrm{G}_{13}$ & $\mathrm{G}_{23}$ & $\nu_{21}$ & $\nu_{21}$ & $\nu_{13}$ & $\nu_{31}$ & $\nu_{23}$ & $\nu_{32}$ \\
\hline coated fiber, $0^{\circ}$ & 26.40 & 11.42 & 6.77 & 7.58 & 3.29 & 1.90 & 0.255 & 0.110 & 0.306 & 0.079 & 0.258 & 0.153 \\
\hline coated fiber, $45^{\circ}$ & 20.81 & 11.74 & 9.51 & 5.36 & 4.51 & 4.31 & 0.201 & 0.114 & 0.391 & 0.179 & 0.208 & 0.168 \\
\hline lamella, $0^{\circ}$ & 26.15 & 11.38 & 6.73 & 7.53 & 3.27 & 1.89 & 0.253 & 0.111 & 0.306 & 0.079 & 0.258 & 0.153 \\
\hline lamella, $45^{\circ}$ & 20.64 & 11.70 & 9.45 & 5.34 & 4.48 & 4.29 & 0.200 & 0.114 & 0.391 & 0.179 & 0.208 & 0.168 \\
\hline
\end{tabular}

Table 2. Effective Elastic Modulus of the Osteon RVE in the Direction of Indentation for Different Lamellar CFO Scenarios and Elastic Moduli of Interstitial Bone

$\begin{array}{lrc}\text { CFO }(\text { deg }) & E(\text { interstitial })(\mathrm{GPa}) & E(\text { effective })(\mathrm{GPa}) \\ 0 & 30.07 & 25.75 \\ 0 & 27.08 & 24.66 \\ 0 & 23.74 & 23.44 \\ 45 & 30.07 & 22.66 \\ 45 & 27.08 & 21.57 \\ 45 & 23.74 & 20.35 \\ 0,45,-45 & 30.07 & 24.10 \\ 0,45,-45 & 27.08 & 23.01 \\ 0,45,-45 & 23.74 & 21.79\end{array}$

remodeling regulator that guides the remodeling activity. Previous studies have shown that osteons targeted by osteoclasts have lower elastic moduli and hardness and are characterized by a lower mineral quantity than nonresorbable areas. ${ }^{78}$ Applying these findings to our study implicates that osteons composed of longitudinally oriented collagen fibers with a higher mineral content are considered more desirable in certain loading scenarios and less prone to osteoclast-mediated bone resorption. As a consequence, our data could be indicative of the fact that osteoclastic resorption does not proceed in a random manner and serves more functions apart from the removal of microdamage. Additionally, the CFO and compositional heterogeneity between dark and bright osteons could promote the detection of microdamage; as deformation can spread out over greater distances due to the nanoscale heterogeneity of the bone matrix, the mechano-sensitive osteocytes, residing inside the bone matrix and sampling their mechanical environment might detect damage and initiate remodeling processes more quickly. ${ }^{79-82}$

While our study used high-resolution techniques to assess changes in the structure, composition, and mechanical properties in individual osteons of contrasting orientation, the osteons were selected from the femoral cross-section of one individual. Therefore, interindividual variations by genetic predisposition, environmental factors, and lifestyle choices may have not been addressed. However, the focus of this study was to approach the compositional changes accompanied by different collagen orientations. By confining to one individual, we were able to focus and address these changes and eliminate potential interindividual factors of influence. Also, CPL reflects the predominant $\mathrm{CFO}$ without direct visualization of the collagen fibers and, hence, provides only an average measure of the CFO. However, in combination with phase-contrast nanocomputed tomography and FIB-SEM imaging, the variability in ultrastructural matrix organization was confirmed in three dimensions and at high-resolution. It was shown that CPL is an imaging modality that is able to indirectly visualize variations in $\mathrm{CFO}$ at the nanoscale. Moreover, in order to implement our spatially correlated analytical approach to evaluate multiple bone quality parameters in the same plane of selected osteons, the use of undecalcified bone specimen was necessary. Hence, the mineral phase is also included in the nanotomograms and contributes to the structural appearance. However, it has been shown that the orientations of mineral particles and collagen fibers are dependent on each other with the crystallographic c-axes being aligned with the fiber axes, so that the collagen fiber orientation can be inferred. ${ }^{10,50,83}$ Therefore, despite not resolving individual collagen fibrils, phase contrast tomography provides sufficient resolution and high sensitivity to mass density fluctuations that allows for the assessment of the ultrastructural matrix organization. Finally, the amount of collagen- and mineral-bound water could not be directly assessed which is known to affect the mechanical properties. ${ }^{84,85}$ It has been shown that the water content is inversely correlated with the mineral content as collagenbound water is gradually replaced by hydroxyapatite. ${ }^{86}$ As we quantified a lower mean and peak mineral content in bright osteons, it can be inferred that these osteons contain a higher amount of bound water. Previous studies have demonstrated that bound water is a substantial contributing factor to the mechanical behavior of bone as it provides collagen ductility and postyield toughness. ${ }^{87,88}$ This further supports our findings that bright osteons provide the bone matrix enhanced ductility and energy dissipating abilities. Further studies both in silico and ex vivo are needed to elucidate the role of dark and bright osteons on fracture mechanics on larger length scales and the whole bone level.

\section{CONCLUSION}

It is commonly accepted that dark osteons are found in regions of tensile stress and bright osteons in regions under compression. Here, we have shown that these osteon types show distinct structural and compositional differences reflecting important mechanical characteristics that locally adapt the bone matrix to its mechanical environment. In particular, dark osteons with longitudinally oriented collagen fibers and a higher degree of mineralization constitute to more stiffness and the ability to resist elastic and plastic deformation in tension and compression whereas bright osteons with oblique-angled fibers provide ductility and the ability to dissipate energy more efficiently where needed. Furthermore, we show that beyond the change in preferential collagen fiber orientation there are fundamental disparities between different types of osteons that result in altered mechanical competence potentially serving as an additional fracture resistance mechanism.

\section{METHODS}

Sample Collection. Healthy femoral bone was obtained during autopsy at the Department of Forensic Medicine at the University Medical Center Hamburg-Eppendorf (Hamburg, Germany) from a 
44-year old organ donor in line with previously published protocols (PV 3486).${ }^{19}$ Femoral cross sections from the mid-diaphysis were cut using a diamond saw (EXAKT Advanced Technologies GmbH, Norderstedt, Germany) and fixed in 3.7\% formaldehyde for 3 days. Thereafter, the sample was dehydrated in an increasing alcohol series and embedded undecalcified in glycolmethacrylate (Technovit 7200, Heraeus Kulzer GmbH, Wehrheim, Germany). Using an automatic grinding machine (EXACT Advances Technologies GmbH, Norderstedt, Germany) the sample was ground to a thickness of $100 \mu \mathrm{m}$.

Circularly Polarized Light Microscopy. Using circularly polarized light microscopy (CPL), the predominant CFO can be visualized. When viewed under polarized light, osteons composed of oblique orientated collagen fibers appear bright, while osteons composed of collagen fibers parallel with the osteon axis appear dark. An Olympus BX-61 microscope (Olympus Europa, Hamburg, Germany) equipped with circularly polarizing filter sets was used to discern dark and bright osteons of different preferential collagen orientation. Prior to any other measurements, a total of 20 (10 dark and 10 bright) fully remodeled osteons with an uninterrupted periphery were selected unbiasedly from the anterolateral quadrant of the cross-section for subsequent structural, compositional and mechanical analysis. By adhering to one bone region a selection bias of osteons that might be subjected to variational mechanical characteristics on a regional bone level is avoided. To exclude primary osteons from the analysis, osteons were selected only if they were surrounded by at least two partially resorbed osteons. An uninterrupted periphery in form of a hypermineralized cement line was further verified using quantitative backscattered electron imaging. In the analyzed area, $14.59 \%$ and $17.52 \%$ of all osteons that matched the selection criteria appeared fully dark and bright, respectively. Haversian canals and surrounding interstitial bone were masked and assigned a gray value of 0 . The grayscale of the bone pixels in each masked osteon was measured and reported as the average brightness (based on gray levels 1-255). To confirm that the osteons included in the study were oriented perpendicular to the analyzed crosssectional plane, microcomputed tomography was performed where the orientation of the Haversian canal was assessed in the orthogonal projections (Figure S4). Finally, to verify that the brightness variations detected by CPL are attributable to changes in preferential CFO and to deconvolute the influence of localized differences in bone mineral density, a control experiment comparing undecalcified and decalcified ground sections in terms of CPL brightness was performed. The anterior quadrant of a femoral cross-section was divided into two parts, and one-half was decalcified in 20\% EDTA for 8 days. Successful decalcification of the sample was checked radiographically using a cabinet X-ray system (Faxitron, Inc., USA). Further sample preparation toward ground sections was identical and as described above.

Quantitative Backscattered Electron Imaging. Quantitative backscattered electron imaging ( $\mathrm{qBEI}$ ) was applied to evaluate the osteonal bone mineral density distribution (BMDD) and morphology of osteocyte lacunae. The coplanar polished surface of the bone specimen was carbon-coated, and the sample was mounted in a scanning electron microscope (GeminiSEM, Zeiss AG, Oberkochen, Germany). The microscope was operated in backscattered electron mode at $20 \mathrm{keV}$ and at a constant working distance of $20 \mathrm{~mm}$. Images were acquired with $300 \times$ magnification. The intensity of backscattered electrons correlates with the mean atomic number of the investigated material. ${ }^{89,48}$ Brightness and contrast of the recorded 8bit images were calibrated using carbon and aluminum standards: the gray values assigned to carbon and aluminum were 4.8 and 222, respectively. As the gray value of unmineralized osteoid $(<0.2 \mathrm{wt} \%$ calcium) was measured to be 4.8 and that of pure hydroxyapatite ( 39.68 wt $\%$ calcium) was 255 , the measurement accuracy was $0.16 \mathrm{wt}$ $\%$ calcium. ${ }^{89}$ The obtained gray values for each pixel were averaged to provide a mean value for the full osteon. Osteonal areas were isolated and surrounding tissue was excluded from evaluation. The following compositional $\mathrm{qBEI}$ parameters were derived from the backscattered electron images using a custom-made MATLAB routine: Mean calcium content of the BMDD $\left(\mathrm{Ca}_{\text {mean }}\right)$, most frequent calcium content $\left(\mathrm{Ca}_{\text {peak }}\right)$, percentage of bone area which is mineralized below the fifth percentile or above the 95th percentile $\left(\mathrm{Ca}_{\text {low }}\right.$ and $\left.\mathrm{Ca}_{\text {high }}\right)$. Additionally, the area, circularity index and density of osteocyte lacunae were assessed.

Focused Ion Beam-Scanning Electron Microscopy. Focused ion beam-scanning electron microscopy (FIB-SEM) imaging was used to visualize the internal structure within dark and bright osteons (Crossbeam 340, Zeiss AG, Oberkochen, Germany). ${ }^{48}$ Using the secondary electron mode, ion milling was performed to expose imaging planes with radial-longitudinal orientation with respect to the Haversian canal. A coarse trench was milled at $30 \mathrm{kV}$ and $30 \mathrm{nA}$, followed by polishing of the exposed image plane at $30 \mathrm{kV}$ and $2 \mathrm{nA}$. Finally, images were acquired at $2 \mathrm{kV}$ (InlensDuo, Zeiss) and postprocessed using a band-pass filter to remove curtaining artifacts. ${ }^{90}$

Fourier Transform Infrared Spectroscopy. Fourier transform infrared spectroscopy (FTIR) in attenuated total reflection-mode was performed to assess the composition of the individual osteons. ${ }^{76}$ FTIR spectra were collected with a FTIR Spotlight 400 (PerkinElmer, Waltham, Massachusetts, USA) over an area of $750 \times 750 \mu \mathrm{m}$ to create a map, where each pixel represents individual spectra. For each osteon, spectra were acquired at a $6.25 \mu \mathrm{m}$ spatial resolution over a spectral range of $4000-570 \mathrm{~cm}^{-1}$ at a resolution of $4 \mathrm{~cm}^{-1}$ and with 16 scans per pixel averaged. The areas under the curve of the amide I peak $\left(1700-1600 \mathrm{~cm}^{-1}\right)$, the phosphate peak $\left(1154-900 \mathrm{~cm}^{-1}\right)$ and the carbohydrate peak $\left(890-850 \mathrm{~cm}^{-1}\right)$ were integrated to measure the mineral-to-matrix ratio (MMR) and carbonate-to-phosphate ratio (CPR). ${ }^{76}$ To account for baseline shifts a local baseline has been used for each integrated peak. Two basepoints at local minima have been selected for the carbonate peak $\left(894-800 \mathrm{~cm}^{-1}\right)$, for the phosphate peak $\left(1182-800 \mathrm{~cm}^{-1}\right)$ and for the amide I peak $\left(1780-1182 \mathrm{~cm}^{-1}\right)$. Only the enclosed area between the respective local baseline and the spectrum was used for integration and calculation of the ratios. Osteonal areas were isolated and surrounding tissue was excluded from evaluation.

Nanoindentation Testing. Nanoindentation testing (G200, Keysight Technologies, Santa Rosa, CA) was used for biomechanical assessment of the individual osteons. ${ }^{48}$ For each osteon, four indents, one per osteonal quadrant, were performed at half the distance between the osteon center and periphery. Using a depth-sensing continuous stiffness method, indentations with $2 \mu \mathrm{m}$ depth were performed with a Berkovich tip preceded and followed by calibration on fused silica. The hardness $\mathrm{H}$ and the elastic modulus $\mathrm{E}$ were calculated according to Oliver and Pharr with the NanoSuite software provided by the manufacturer. $^{91}$

Synchrotron Nanocomputed Tomography. Synchrotron nanocomputed tomography with Zernike phase contrast was performed at the P05 beamline ${ }^{92,93}$ operated by the Helmholtz Zentrum Geesthacht (HZG) at the PETRA III storage ring of the German Electron Synchrotron (DESY) to visualize the ultrastructural organization of 16 osteons ( $n=8$ per group) beneath the nanoindentations in $3 \mathrm{D} .{ }^{49,50}$ The samples were prepared using FIBSEM. The nanoindentations were localized and cylindrical volumes with a diameter of $25 \mu \mathrm{m}$ were extracted and placed on a cone-shaped sample holder using a micromanipulator. A full field transmission Xray microscope equipped with a Fresnel Zone Plate of $130 \mu \mathrm{m}$ diameter, a beam shaping optics and Zernike phase rings, was used for acquiring the tomograms at an energy of $11 \mathrm{keV}$. These optics were designed and manufactured at the Paul Scherrer Institute. An X-ray sCMOS camera (Hamamatsu C12849-101U, $6.5 \mu$ m pixel size, 2048 $\times 2048$ pixel, 16 bit image depth) with a $10 \mu \mathrm{m}$ Gadox scintillator was used as a detector. The effective pixel size of the system was $18.65 \mathrm{~nm}$ and a binning factor of 2 was applied. The resolution was determined in 3D using Fourier Shell correlations (FSCs). By applying the 1/2-bit criterion, the average FSC-based spatial resolution was calculated to be $77.7 \mathrm{~nm}$. To ensure that the ultrastructural organization is not affected by plastic deformation below the nanoindent, the analyzed volume of interest was chosen to start $5 \mu \mathrm{m}$ below the sample surface.

Finite Element Modeling. To predict how the mechanical properties of bone at different hierarchical levels are affected by changes in the predominant CFO, multiscale modeling using the 
Finite Element Method (FEM) was applied. ${ }^{94-96}$ Periodic boundary conditions (PBCs) were applied to simulate the orthotropic mechanical properties in different hierarchical levels by modeling finite representative volume elements (RVEs). ${ }^{97}$ Here, the hierarchical levels of (i) mineral-coated collagen fibers, (ii) osteonal lamellae, and (iii) remodeled secondary osteons were modeled based on two different orientations of mineralized collagen fibrils $\left(0^{\circ}\right.$ and $\left.45^{\circ}\right)$ to represent dark and bright osteons. The volume fractions of the coated fiber level (87.4\% mineralized collagen fibril, $12.6 \%$ extrafibrillar hydroxyapatite) and the orthotropic elastic constants of mineralized collagen fibrils were adapted from Hamed et al. ${ }^{98,99}$ The hydroxyapatite foam was assumed to be isotropic with the bulk and shear modulus being $K_{\mathrm{HA}}=57.8 \mathrm{GPa}$ and $\mu_{\mathrm{HA}}=31.4 \mathrm{GPa}$, respectively. ${ }^{100}$ Osteonal lamellae were composed of the homogenized coated fiber RVE (97.5\% volume fraction) interspersed with ellipsoidal lacunar cavities $(2.25 \%)^{101}$ with a mean size of $18.9 \mu \mathrm{m} \times$ $9.2 \mu \mathrm{m} \times 4.8 \mu \mathrm{m} .{ }^{102}$ The characteristics for the osteon RVE were extracted from the qBEI images (osteon diameter $=300 \mu \mathrm{m}$, Haversian canal diameter $=90 \mu \mathrm{m}$, lamellar thickness $=6 \mu \mathrm{m}$, number of lamellae = 11). Each lamella was assigned a collagen fiber orientation of $0^{\circ}$ or $45^{\circ}$. Three scenarios of CFO were considered: (1) all lamellae contain collagen fibers with $0^{\circ}$ orientation (dark osteon), (2) all lamellae contain fibers oriented $45^{\circ}$ (bright osteon), and (3) lamellae alternate in terms of CFO between $0^{\circ}$ and $45^{\circ}$. Three elastic moduli were assumed for the stiffer surrounding interstitial bone $\left(+15 \%\right.$ of elastic modulus of osteonal bone with $0^{\circ}$, $25^{\circ}$, and $45^{\circ}$ orientation corresponding to $30.07,27.08$, and 23.74 GPa, respectively). ${ }^{103}$ Nine orthotropic material properties according to the elastic material stress-strain relation were calculated at each hierarchical level.

ABAQUS/CAE 6.14-4 was used to create the RVEs. The General/ Static solver was employed for the computation and the mesh independency has been checked for the solution to be converged. 11900 and 47421 eight-node linear brick elements with reduced integration (C3D8R) were used to mesh the coated fiber and osteon RVE, respectively. The osteonal lamellae were meshed with 1198310 node quadratic tetrahedron elements (C3D10). A python script was developed to calculate the average stress and strain components within the model to numerically compute the mechanical properties of the homogenized RVE.

Statistical Analysis. Normality of the data was assessed by Shapiro-Wilk tests. To determine statistical differences between dark and bright osteons independent $t$ tests were performed. Pearson product-moment correlations were used to check for correlations between structural, compositional, and mechanical properties. Statistical tests were performed using SPSS with a level of significance of $\alpha=0.05$.

\section{ASSOCIATED CONTENT}

\section{SI Supporting Information}

The Supporting Information is available free of charge at https://pubs.acs.org/doi/10.1021/acsnano.0c04786.

$3 \mathrm{D}$ assessment of osteon orientation by coregistration of microcomputed tomography scan and CPL micrograph, CPL micrographs comparing undecalcified and decalcified ground sections, spatial assessment of canalicular network by nanocomputed tomography, and spatial distribution of high-MMR zone (PDF)

Video of nanocomputed tomography stack obtained from a dark osteon (MP4)

Video of nanocomputed tomography stack obtained from a bright osteon (MP4)

\section{AUTHOR INFORMATION}

\section{Corresponding Author}

Björn Busse - Department of Osteology and Biomechanics, University Medical Center, 22529 Hamburg, Germany;
Interdisciplinary Competence Center for Interface Research (ICCIR), 20251 Hamburg, Germany; Materials Sciences Division, Lawrence Berkeley National Laboratory, Berkeley, California 94720, United States; 이이이.org/0000-0002-

3099-8073; Email: b.busse@uke.uni-hamburg.de

\section{Authors}

Kilian E. Stockhausen - Department of Osteology and Biomechanics, University Medical Center, 22529 Hamburg, Germany; 이이이.org/0000-0001-8923-8936

Mahan Qwamizadeh - Department of Osteology and Biomechanics, University Medical Center, 22529 Hamburg, Germany

Eva M. Wölfel - Department of Osteology and Biomechanics, University Medical Center, 22529 Hamburg, Germany; Forum Medical Technology Health Hamburg (FMTHH), 22529 Hamburg, Germany; Interdisciplinary Competence Center for Interface Research (ICCIR), 20251 Hamburg, Germany

Haniyeh Hemmatian - Department of Osteology and Biomechanics, University Medical Center, 22529 Hamburg, Germany

Imke A. K. Fiedler - Department of Osteology and Biomechanics, University Medical Center, 22529 Hamburg, Germany; Forum Medical Technology Health Hamburg (FMTHH), 22529 Hamburg, Germany

Silja Flenner - Institute of Materials Research, HelmholtzZentrum Geesthacht, 21502 Geesthacht, Germany

Elena Longo - Institute of Materials Research, HelmholtzZentrum Geesthacht, 21502 Geesthacht, Germany

Michael Amling - Department of Osteology and Biomechanics, University Medical Center, 22529 Hamburg, Germany

Imke Greving - Institute of Materials Research, HelmholtzZentrum Geesthacht, 21502 Geesthacht, Germany

Robert O. Ritchie - Materials Sciences Division, Lawrence Berkeley National Laboratory, Berkeley, California 94720, United States; ○ orcid.org/0000-0002-0501-6998

Felix N. Schmidt - Department of Osteology and Biomechanics, University Medical Center, 22529 Hamburg, Germany; Forum Medical Technology Health Hamburg (FMTHH), 22529 Hamburg, Germany

Complete contact information is available at: https://pubs.acs.org/10.1021/acsnano.0c04786

\section{Author Contributions}

${ }^{\#}$ F.N.S. and B.B. contributed equally.

\section{Notes}

The authors declare no competing financial interest.

\section{ACKNOWLEDGMENTS}

We acknowledge the Helmholtz-Zentrum Geesthacht outstation at DESY (Hamburg, Germany), a member of the Helmholtz Association HGF, for the provision of experimental facilities. Parts of this research were carried out at the Imaging Beamline P05 at PETRA III, and we thank D. Laipple for assistance in the sample preparation. We acknowledge the input and support on the study by K. Püschel, A. vom Scheidt and C. Plumeyer. M.Q. and H.H. are fellows of the Alexander von Humboldt foundation. B.B. is supported by the German Research Foundation (DFG) under Grant No. BU 2562/3-1. I.G. and E.L. acknowledge funding by the German Research 
Foundation (DFG) under Grant No. 192346071 - SFB 986, Z2. Further funding was received from the Interdisciplinary Center for Interface Research (ICCIR) on behalf of the Hamburg University of Technology (TUHH) and the University Medical Center Hamburg-Eppendorf (UKE).

\section{REFERENCES}

(1) Milovanovic, P.; Busse, B. Inter-site Variability of the Human Osteocyte Lacunar Network: Implications for Bone Quality. Curr Osteoporos Rep. 2019, 17 (3), 105-115.

(2) Milovanovic, P.; Busse, B. Phenomenon of osteocyte lacunar mineralization: indicator of former osteocyte death and a novel marker of impaired bone quality? Endocr. Connect. 2020, 9 (4), R70R80.

(3) Lassen, N. E.; Andersen, T. L.; Pløen, G. G.; Søe, K.; Hauge, E. M.; Harving, S.; Eschen, G. E. T.; Delaisse, J.-M. Coupling of Bone Resorption and Formation in Real Time: New Knowledge Gained from Human Haversian BMUs. J. Bone Miner. Res. 2017, 32, 13951405.

(4) Gebhardt, W. Über Funktionell Wichtige Anordnungsweisen Der Feineren Und Gröberen Bauelemente Des Wirbeltierknochens. Dev. Genes Evol. 1905, 20, 187-322.

(5) Ascenzi, A.; Bonucci, E. The Compressive Properties of Single Osteons. Anat. Rec. 1968, 161, 377-391.

(6) Ascenzi, A.; Bonucci, E. The Tensile Properties of Single Osteons. Anat. Rec. 1967, 158, 375-386.

(7) Giraud-Guille, M. M. Twisted Plywood Architecture of Collagen Fibrils in Human Compact Bone Osteons. Calcif. Tissue Int. 1988, 42, 167-180.

(8) Reznikov, N.; Shahar, R.; Weiner, S. Bone Hierarchical Structure in Three Dimensions. Acta Biomater. 2014, 10, 3815-3826.

(9) Fratzl, P.; Gupta, H. S.; Paschalis, E. P.; Roschger, P. Structure and Mechanical Quality of the Collagen-Mineral Nano-Composite in Bone. J. Mater. Chem. 2004, 14, 2115-2123.

(10) McNally, E.; Nan, F.; Botton, G. A.; Schwarcz, H. P. Scanning Transmission Electron Microscopic Tomography of Cortical Bone Using Z-Contrast Imaging. Micron 2013, 49, 46-53.

(11) Reznikov, N.; Bilton, M.; Lari, L.; Stevens, M. M.; Kröger, R. Fractal-Like Hierarchical Organization of Bone Begins at the Nanoscale. Science 2018, 360, eaao2189.

(12) Grünewald, T. A.; Liebi, M.; Wittig, N. K.; Johannes, A.; Sikjaer, T.; Rejnmark, L.; Gao, Z.; Rosenthal, M.; Guizar-Sicairos, M.; Birkedal, H.; Burghammer, M. Mapping the 3D Orientation of Nanocrystals and Nanostructures in Human Bone: Indications of Novel Structural Features. Sci. Adv. 2020, 6, eaba4171.

(13) Lefèvre, E.; Farlay, D.; Bala, Y.; Subtil, F.; Wolfram, U.; Rizzo, S.; Baron, C.; Zysset, P.; Pithioux, M.; Follet, H. Compositional and Mechanical Properties of Growing Cortical Bone Tissue: A Study of the Human Fibula. Sci. Rep. 2019, 9, 17639.

(14) Zimmermann, E. A.; Riedel, C.; Schmidt, F. N.; Stockhausen, K. E.; Chushkin, Y.; Schaible, E.; Gludovatz, B.; Vettorazzi, E.; Zontone, F.; Püschel, K.; Amling, M.; Ritchie, R. O.; Busse, B. Mechanical Competence and Bone Quality Develop during Skeletal Growth. J. Bone Miner. Res. 2019, 34, 1461-1472.

(15) Zimmermann, E. A.; Ritchie, R. O. Bone as a Structural Material. Adv. Healthcare Mater. 2015, 4, 1287-1304.

(16) Zimmermann, E. A.; Schaible, E.; Bale, H.; Barth, H. D.; Tang, S. Y.; Reichert, P.; Busse, B.; Alliston, T.; Ager, J. W.; Ritchie, R. O. Age-Related Changes in the Plasticity and Toughness of Human Cortical Bone at Multiple Length Scales. Proc. Natl. Acad. Sci. U. S. A. 2011, 108, 14416-14421.

(17) Zimmermann, E. A.; Busse, B.; Ritchie, R. O. The Fracture Mechanics of Human Bone: Influence of Disease and Treatment. BoneKEy Rep. 2015, 4, 743.

(18) Vom Scheidt, A.; Hemmatian, H.; Püschel, K.; Krause, M.; Amling, M.; Busse, B. Bisphosphonate Treatment Changes Regional Distribution of Trabecular Microstructure in Human Lumbar Vertebrae. Bone 2019, 127, 482-487.
(19) Milovanovic, P.; Zimmermann, E. A.; Riedel, C.; vom Scheidt, A.; Herzog, L.; Krause, M.; Djonic, D.; Djuric, M.; Puschel, K.; Amling, M.; Ritchie, R. O.; Busse, B. Multi-Level Characterization of Human Femoral Cortices and Their Underlying Osteocyte Network Reveal Trends in Quality of Young, Aged, Osteoporotic and Antiresorptive-Treated Bone. Biomaterials 2015, 45, 46-55.

(20) McCalden, R. W.; McGeough, J. A.; Barker, M. B.; CourtBrown, C. M. Age-Related Changes in the Tensile Properties of Cortical Bone. The Relative Importance of Changes in Porosity, Mineralization, and Microstructure. J. Bone Joint Surg. Am. 1993, 75, $1193-1205$.

(21) O’Brien, F. J.; Taylor, D.; Lee, T. C. Microcrack Accumulation at Different Intervals during Fatigue Testing of Compact Bone. J. Biomech. 2003, 36, 973-980.

(22) Willett, T. L.; Dapaah, D. Y.; Uppuganti, S.; Granke, M.; Nyman, J. S. Bone Collagen Network Integrity and Transverse Fracture Toughness of Human Cortical Bone. Bone 2019, 120, 187193.

(23) Fiedler, I. A. K.; Schmidt, F. N.; Wölfel, E. M.; Plumeyer, C.; Milovanovic, P.; Gioia, R.; Tonelli, F.; Bale, H. A.; Jähn, K.; Besio, R.; Forlino, A.; Busse, B. Severely Impaired Bone Material Quality in Chihuahua Zebrafish Resembles Classical Dominant Human Osteogenesis Imperfecta. J. Bone Miner. Res. 2018, 33, 1489-1499.

(24) Wang, X.; Shen, X.; Li, X.; Agrawal, C. M. Age-Related Changes in the Collagen Network and Toughness of Bone. Bone 2002, 31, 17.

(25) Carriero, A.; Zimmermann, E. A.; Paluszny, A.; Tang, S. Y.; Bale, H.; Busse, B.; Alliston, T.; Kazakia, G.; Ritchie, R. O.; Shefelbine, S. J. How Tough Is Brittle Bone? Investigating Osteogenesis Imperfecta in Mouse Bone. J. Bone Miner. Res. 2014, 29, 1392-1401.

(26) Rauch, F.; Glorieux, F. H. Osteogenesis Imperfecta. Lancet 2004, 363, 1377-1385.

(27) Zimmermann, E. A.; Köhne, T.; Bale, H. A.; Panganiban, B.; Gludovatz, B.; Zustin, J.; Hahn, M.; Amling, M.; Ritchie, R. O.; Busse, B. Modifications to Nano- and Microstructural Quality and the Effects on Mechanical Integrity in Paget's Disease of Bone. J. Bone Miner. Res. 2015, 30, 264-273.

(28) Viguet-Carrin, S.; Garnero, P.; Delmas, P. D. The Role of Collagen in Bone Strength. Osteoporosis Int. 2006, 17, 319-336.

(29) Ritchie, R. O. The Conflicts between Strength and Toughness. Nat. Mater. 2011, 10, 817-822.

(30) Bromage, T. G.; Goldman, H. M.; McFarlin, S. C.; Warshaw, J.; Boyde, A.; Riggs, C. M. Circularly Polarized Light Standards for Investigations of Collagen Fiber Orientation in Bone. Anat. Rec. 2003, 274, 157-168.

(31) Ascenzi, M. G.; Ascenzi, A.; Benvenuti, A.; Burghammer, M.; Panzavolta, S.; Bigi, A. Structural Differences between "Dark" and "Bright" Isolated Human Osteonic Lamellae. J. Struct. Biol. 2003, 141, $22-33$.

(32) McMahon, J. M.; Boyde, A.; Bromage, T. G. Pattern of Collagen Fiber Orientation in the Ovine Calcaneal Shaft and Its Relation to Locomotor-Induced Strain. Anat. Rec. 1995, 242, 147158.

(33) Riggs, C. M.; Vaughan, L. C.; Evans, G. P.; Lanyon, L. E.; Boyde, A. Mechanical Implications of Collagen Fibre Orientation in Cortical Bone of the Equine Radius. Anat. Embryol. 1993, 187, 239248

(34) Ascenzi, A. The Micromechanics versus the Macromechanics of Cortical Bone - A Comprehensive Presentation. J. Biomech. Eng. 1988, 110, 357-363.

(35) Martin, R. B.; Ishida, J. The Relative Effects of Collagen Fiber Orientation, Porosity, Density, and Mineralization on Bone Strength. J. Biomech. 1989, 22, 419-426.

(36) Martin, R. B.; Boardman, D. L. The Effects of Collagen Fiber Orientation, Porosity, Density, and Mineralization on Bovine Cortical Bone Bending Properties. J. Biomech. 1993, 26, 1047-1054. 
(37) Shahar, R.; Banks-Sills, L.; Eliasy, R. Stress and Strain Distribution in the Intact Canine Femur: Finite Element Analysis. Med. Eng. Phys. 2003, 25, 387-395.

(38) Bergmann, G.; Siraky, J.; Rohlmann, A.; Koelbel, R. A Comparison of Hip Joint Forces in Sheep, Dog and Man. J. Biomech. 1984, 17, 907-921.

(39) Boyde, A.; Riggs, C. M. The Quantitative Study of the Orientation of Collagen in Compact Bone Slices. Bone 1990, 11, 3539.

(40) Skedros, J. G.; Mason, M. W.; Nelson, M. C.; Bloebaum, R. D. Evidence of Structural and Material Adaptation to Specific Strain Features in Cortical Bone. Anat. Rec. 1996, 246, 47-63.

(41) Mason, M. W.; Skedros, J. G.; Bloebaum, R. D. Evidence of Strain-Mode-Related Cortical Adaptation in the Diaphysis of the Horse Radius. Bone 1995, 17, 229-237.

(42) Riggs, C. M.; Lanyon, L. E.; Boyde, A. Functional Associations between Collagen Fibre Orientation and Locomotor Strain Direction in Cortical Bone of the Equine Radius. Anat. Embryol. 1993, 187, 231-238.

(43) Skedros, J. G.; Mendenhall, S. D.; Kiser, C. J.; Winet, H. Interpreting Cortical Bone Adaptation and Load History by Quantifying Osteon Morphotypes in Circularly Polarized Light Images. Bone 2009, 44, 392-403.

(44) Skedros, J. G.; Kiser, C. J.; Mendenhall, S. D. A Weighted Osteon Morphotype Score Outperforms Regional Osteon Percent Prevalence Calculations for Interpreting Cortical Bone Adaptation. Am. J. Phys. Anthropol. 2011, 144, 41-50.

(45) Duda, G. N.; Schneider, E.; Chao, E. Y. S. Internal Forces and Moments in the Femur during Walking. J. Biomech. 1997, 30, 933941.

(46) Taylor, M. E.; Tanner, K. E.; Freeman, M. A.; Yettram, A. L. Stress and Strain Distribution within the Intact Femur: Compression or Bending? Med. Eng. Phys. 1996, 18, 122-131.

(47) Zheng, N.; Fleisig, G. S.; Escamilla, R. F.; Barrentine, S. W. An Analytical Model of the Knee for Estimation of Internal Forces during Exercise. J. Biomech. 1998, 31, 963-967.

(48) Zimmermann, E. A.; Fiedler, I. A. K.; Busse, B. Breaking new ground in mineralized tissue: Assessing tissue quality in clinical and laboratory studies. J. Mech. Behav. Biomed. Mater. 2021, 113, 104138.

(49) Langer, M.; Pacureanu, A.; Suhonen, H.; Grimal, Q.; Cloetens, P.; Peyrin, F. X-Ray Phase Nanotomography Resolves the 3D Human Bone Ultrastructure. PLoS One 2012, 7, 1-7.

(50) Varga, P.; Pacureanu, A.; Langer, M.; Suhonen, H.; Hesse, B.; Grimal, Q.; Cloetens, P.; Raum, K.; Peyrin, F. Investigation of the Three-Dimensional Orientation of Mineralized Collagen Fibrils in Human Lamellar Bone Using Synchrotron X-Ray Phase NanoTomography. Acta Biomater. 2013, 9, 8118-8127.

(51) Reznikov, N.; Shahar, R.; Weiner, S. Three-Dimensional Structure of Human Lamellar Bone: The Presence of Two Different Materials and New Insights into the Hierarchical Organization. Bone 2014, 59, 93-104.

(52) Grandfield, K.; Vuong, V.; Schwarcz, H. P. Ultrastructure of Bone: Hierarchical Features from Nanometer to Micrometer Scale Revealed in Focused Ion Beam Sections in the TEM. Calcif. Tissue Int. 2018, 103, 606-616.

(53) Pazzaglia, U. E.; Congiu, T.; Marchese, M.; Spagnuolo, F.; Quacci, D. Morphometry and Patterns of Lamellar Bone in Human Haversian Systems. Anat. Rec. 2012, 295, 1421-1429.

(54) Jones, S. J.; Boyde, A.; Pawley, J. B. Osteoblasts and Collagen Orientation. Cell Tissue Res. 1975, 159, 73-80.

(55) Kerschnitzki, M.; Wagermaier, W.; Roschger, P.; Seto, J.; Shahar, R.; Duda, G. N.; Mundlos, S.; Fratzl, P. The Organization of the Osteocyte Network Mirrors the Extracellular Matrix Orientation in Bone. J. Struct. Biol. 2011, 173, 303-311.

(56) Currey, J. D. The Adaption of Mechanical Properties to Different Functions. Bones: Structure and Mechanics, 2nd ed.; Princeton University Press, 2002; Vol. 2, pp 144-145.
(57) Bala, Y.; Farlay, D.; Delmas, P. D.; Meunier, P. J.; Boivin, G. Time Sequence of Secondary Mineralization and Microhardness in Cortical and Cancellous Bone from Ewes. Bone 2010, 46, 1204-1212.

(58) Grynpas, M. Age and Disease-Related Changes in the Mineral of Bone. Calcif. Tissue Int. 1993, 53, 57-64.

(59) Busse, B.; Bale, H. A.; Zimmermann, E. A.; Panganiban, B.; Barth, H. D.; Carriero, A.; Vettorazzi, E.; Zustin, J.; Hahn, M.; Ager, J. W.; Püschel, K.; Amling, M.; Ritchie, R. O. Vitamin D Deficiency Induces Early Signs of Aging in Human Bone, Increasing the Risk of Fracture. Sci. Transl. Med. 2013, 5, 188-193.

(60) Schmidt, F. N.; Zimmermann, E. A.; Walsh, F.; Plumeyer, C.; Schaible, E.; Fiedler, I. A. K.; Milovanovic, P.; Rößle, M.; Amling, M.; Blanchet, C.; Gludovatz, B.; Ritchie, R. O.; Busse, B. On the Origins of Fracture Toughness in Advanced Teleosts: How the Swordfish Sword's Bone Structure and Composition Allow for Slashing under Water to Kill or Stun Prey. Adv. Sci. 2019, 6, 1970072.

(61) Wittig, N. K.; Palle, J.; Østergaard, M.; Frølich, S.; Birkbak, M. E.; Spiers, K. M.; Garrevoet, J.; Birkedal, H. Bone Biomineral Properties Vary across Human Osteonal Bone. ACS Nano 2019, 13, 12949-12956.

(62) Roschger, A.; Roschger, P.; Wagermaier, W.; Chen, J.; van Tol, A. F.; Repp, F.; Blouin, S.; Berzlanovich, A.; Gruber, G. M.; Klaushofer, K.; Fratzl, P.; Weinkamer, R. The Contribution of the Pericanalicular Matrix to Mineral Content in Human Osteonal Bone. Bone 2019, 123, 76-85.

(63) Boskey, A. L.; Imbert, L. Bone Quality Changes Associated with Aging and Disease: A Review. Ann. N. Y. Acad. Sci. 2017, 1410, 93-106.

(64) McCreadie, B. R.; Morris, M. D.; Chen, T.; Rao, D. S.; Finney, W. F.; Widjaja, E.; Goldstein, S. A. Bone Tissue Compositional Differences in Women with and without Osteoporotic Fracture. Bone 2006, 39, 1190-1195.

(65) Boskey, A. L.; Donnelly, E.; Boskey, E.; Spevak, L.; Ma, Y.; Zhang, W.; Lappe, J.; Recker, R. R. Examining the Relationships between Bone Tissue Composition, Compositional Heterogeneity, and Fragility Fracture: A Matched Case-Controlled FTIRI Study. J. Bone Miner. Res. 2016, 31, 1070-1081.

(66) Paschalis, E. P.; Betts, F.; DiCarlo, E.; Mendelsohn, R.; Boskey, A. L. FTIR Microspectroscopic Analysis of Normal Human Cortical and Trabecular Bone. Calcif. Tissue Int. 1997, 61, 480-486.

(67) Schmidt, F. N.; Delsmann, M. M.; Mletzko, K.; Yorgan, T. A.; Hahn, M.; Siebert, U.; Busse, B.; Oheim, R.; Amling, M.; Rolvien, T. Ultra-High Matrix Mineralization of Sperm Whale Auditory Ossicles Facilitates High Sound Pressure and High-Frequency Underwater Hearing. Proc. R. Soc. London, Ser. B 2018, 285, 20181820.

(68) Landis, W. J.; Librizzi, J. J.; Dunn, M. G.; Silver, F. H. A Study of the Relationship between Mineral Content and Mechanical Properties of Turkey Gastrocnemius Tendon. J. Bone Miner. Res. 1995, 10, 859-867.

(69) Follet, H.; Boivin, G.; Rumelhart, C.; Meunier, P. The Degree of Mineralization Is a Determinant of Bone Strength: A Study on Human Calcanei. Bone 2004, 34, 783-789.

(70) Donnelly, E.; Boskey, A. L.; Baker, S. P.; van der Meulen, M. C. $\mathrm{H}$. Effects of Tissue Age on Bone Tissue Material Composition and Nanomechanical Properties in the Rat Cortex. J. Biomed. Mater. Res., Part A 2009, 9999A, 1048-1056.

(71) Rho, J. Y.; Zioupos, P.; Currey, J. D.; Pharr, G. M. Microstructural Elasticity and Regional Heterogeneity in Human Femoral Bone of Various Ages Examined by Nano-Indentation. J. Biomech. 2002, 35, 189-198.

(72) Nair, A. K.; Gautieri, A.; Buehler, M. J. Role of Intrafibrillar Collagen Mineralization in Defining the Compressive Properties of Nascent Bone. Biomacromolecules 2014, 15, 2494-2500.

(73) Seref-Ferlengez, Z.; Kennedy, O. D.; Schaffler, M. B. Bone Microdamage, Remodeling and Bone Fragility: How Much Damage Is Too Much Damage? BoneKEy Rep. 2015, 4, 644.

(74) Donnelly, E.; Meredith, D. S.; Nguyen, J. T.; Gladnick, B. P.; Rebolledo, B. J.; Shaffer, A. D.; Lorich, D. G.; Lane, J. M.; Boskey, A. L. Reduced Cortical Bone Compositional Heterogeneity with 
Bisphosphonate Treatment in Postmenopausal Women with Intertrochanteric and Subtrochanteric Fractures. J. Bone Miner. Res. 2012, 27, 672-678.

(75) Boivin, G. Y.; Chavassieux, P. M.; Santora, A. C.; Yates, J.; Meunier, P. J. Alendronate Increases Bone Strength by Increasing the Mean Degree of Mineralization of Bone Tissue in Osteoporotic Women. Bone 2000, 27, 687-694.

(76) Schmidt, F. N.; Zimmermann, E. A.; Campbell, G. M.; Sroga, G. E.; Püschel, K.; Amling, M.; Tang, S. Y.; Vashishth, D.; Busse, B. Assessment of Collagen Quality Associated with Non-Enzymatic Cross-Links in Human Bone Using Fourier-Transform Infrared Imaging. Bone 2017, 97, 243-251.

(77) Milovanovic, P.; vom Scheidt, A.; Mletzko, K.; Sarau, G.; Püschel, K.; Djuric, M.; Amling, M.; Christiansen, S.; Busse, B. Bone Tissue Aging Affects Mineralization of Cement Lines. Bone 2018, 110, 187-193.

(78) Pernelle, K.; Imbert, L.; Bosser, C.; Auregan, J. C.; Cruel, M.; Ogier, A.; Jurdic, P.; Hoc, T. Microscale Mechanical and Mineral Heterogeneity of Human Cortical Bone Governs Osteoclast Activity. Bone 2017, 94, 42-49.

(79) Tai, K.; Dao, M.; Suresh, S.; Palazoglu, A.; Ortiz, C. Nanoscale Heterogeneity Promotes Energy Dissipation in Bone. Nat. Mater. 2007, 6, 454-462.

(80) Klein-Nulend, J.; Bacabac, R. G.; Bakker, A. D. Mechanical Loading and How It Affects Bone Cells: The Role of the Osteocyte Cytoskeleton in Maintaining Our Skeleton. Eur. Cell. Mater. 2012, 24, 278-291.

(81) Klein-Nulend, J.; Bakker, A. D.; Bacabac, R. G.; Vatsa, A.; Weinbaum, S. Mechanosensation and Transduction in Osteocytes. Bone 2013, 54, 182-190.

(82) Milovanovic, P.; Zimmermann, E. A.; Hahn, M.; Djonic, D.; Püschel, K.; Djuric, M.; Amling, M.; Busse, B. Osteocytic Canalicular Networks: Morphological Implications for Altered Mechanosensitivity. ACS Nano 2013, 7, 7542-7551.

(83) Stock, S. R. The Mineral-Collagen Interface in Bone. Calcif. Tissue Int. 2015, 97, 262-280.

(84) Nyman, J. S.; Ni, Q.; Nicolella, D. P.; Wang, X. Measurements of Mobile and Bound Water by Nuclear Magnetic Resonance Correlate with Mechanical Properties of Bone. Bone 2008, 42, 193-199.

(85) Nyman, J. S.; Gorochow, L. E.; Adam Horch, R.; Uppuganti, S.; Zein-Sabatto, A.; Manhard, M. K.; Does, M. D. Partial Removal of Pore and Loosely Bound Water by Low-Energy Drying Decreases Cortical Bone Toughness in Young and Old Donors. J. Mech. Behav. Biomed. Mater. 2013, 22, 136-145.

(86) Wehrli, F. W.; Fernández-Seara, M. A. Nuclear Magnetic Resonance Studies of Bone Water. Ann. Biomed. Eng. 2005, 33, 7986.

(87) Granke, M.; Does, M. D.; Nyman, J. S. The Role of Water Compartments in the Material Properties of Cortical Bone. Calcif. Tissue Int. 2015, 97, 292-307.

(88) Nyman, J. S.; Roy, A.; Shen, X.; Acuna, R. L.; Tyler, J. H.; Wang, X. The Influence of Water Removal on the Strength and Toughness of Cortical Bone. J. Biomech. 2006, 39, 931-938.

(89) Roschger, P.; Fratzl, P.; Eschberger, J.; Klaushofer, K. Validation of Quantitative Backscattered Electron Imaging for the Measurement of Mineral Density Distribution in Human Bone Biopsies. Bone 1998, 23, 319-326.

(90) Schindelin, J.; Arganda-Carreras, I.; Frise, E.; Kaynig, V.; Longair, M.; Pietzsch, T.; Preibisch, S.; Rueden, C.; Saalfeld, S.; Schmid, B.; Tinevez, J.-Y.; White, D. J.; Hartenstein, V.; Eliceiri, K.; Tomancak, P.; Cardona, A. Fiji: An Open-Source Platform for Biological-Image Analysis. Nat. Methods 2012, 9, 676-682.

(91) Oliver, W. C.; Pharr, G. M. An Improved Technique for Determining Hardness and Elastic Modulus Using Load and Displacement Sensing Indentation Experiments. J. Mater. Res. 1992, 7, 1564-1583.

(92) Ogurreck, M.; Wilde, F.; Herzen, J.; Beckmann, F.; Nazmov, V.; Mohr, J.; Haibel, A.; Müller, M.; Schreyer, A. The Nanotomography
Endstation at the PETRA III Imaging Beamline. J. Phys.: Conf. Ser. 2013, 425, 182002.

(93) Flenner, S.; Storm, M.; Kubec, A.; Longo, E.; Döring, F.; Pelt, D. M.; David, C.; Müller, M.; Greving, I. Pushing the Temporal Resolution in Absorption and Zernike Phase Contrast Nanotomography: Enabling Fast In Situ Experiments. J. Synchrotron Radiat. 2020, 27, 1339-1346.

(94) Qwamizadeh, M.; Liu, P.; Zhang, Z.; Zhou, K.; Wei Zhang, Y. Hierarchical Structure Enhances and Tunes the Damping Behavior of Load-Bearing Biological Materials. J. Appl. Mech. 2016, 83, 51009.

(95) Qwamizadeh, M.; Lin, M.; Zhang, Z.; Zhou, K.; Zhang, Y. W. Bounds for the Dynamic Modulus of Unidirectional Composites with Bioinspired Staggered Distributions of Platelets. Compos. Struct. 2017, $167,152-165$.

(96) Qwamizadeh, M.; Zhou, K.; Zhang, Y. W. Damping Behavior Investigation and Optimization of the Structural Layout of LoadBearing Biological Materials. Int. J. Mech. Sci. 2017, 120, 263-275.

(97) Omairey, S. L.; Dunning, P. D.; Sriramula, S. Development of an ABAQUS Plugin Tool for Periodic RVE Homogenisation. Eng. Comput. 2019, 35, 567-577.

(98) Hamed, E.; Jasiuk, I.; Yoo, A.; Lee, Y. H.; Liszka, T. Multi-Scale Modelling of Elastic Moduli of Trabecular Bone. J. R. Soc., Interface 2012, 9, 1654-1673.

(99) Hamed, E.; Lee, Y.; Jasiuk, I. Multiscale Modeling of Elastic Properties of Cortical Bone. Acta Mech. 2010, 213, 131-154.

(100) Hellmich, C.; Ulm, F.-J. Micromechanical Model for Ultrastructural Stiffness of Mineralized Tissues. J. Eng. Mech. 2002, 128, 898-908.

(101) Buenzli, P. R.; Sims, N. A. Quantifying the Osteocyte Network in the Human Skeleton. Bone 2015, 75, 144-150.

(102) Dong, P.; Haupert, S.; Hesse, B.; Langer, M.; Gouttenoire, P.J. J.; Bousson, V. V.; Peyrin, F. F. 3D Osteocyte Lacunar Morphometric Properties and Distributions in Human Femoral Cortical Bone Using Synchrotron Radiation Micro-CT Images. Bone 2014, 60, 172-185.

(103) Rho, J. Y.; Tsui, T. Y.; Pharr, G. M. Elastic Properties of Human Cortical and Trabecular Lamellar Bone Measured by Nanoindentation. Biomaterials 1997, 18, 1325-1330. 